\title{
Pelatihan Kelompok Ibu Menyusui di Desa Penyengat Olak Muaro Jambi Tahun 2019
}

\author{
Yuli Suryanti $^{1}$, Lia Artika Sari ${ }^{2}$, Ika Murtiyarini ${ }^{3}$ \\ 1,2,3 Jurusan Kebidanan, Poltekkes Kemenkes Jambi \\ Email:yulisuryanti_bdn@poltekkesjambi.ac.id
}

\begin{abstract}
Maternal and child health is one of the priority aspects to consider. Based on the results of the 2012 Indonesian Demographic and Health Survey (IDHS), it was shown that the neonates mortality rate in 2012 was 19 per 1000 live births. This problem arises in part related to the problem of breastfeeding. The results of the screening for the nutritional status of toddlers at the posyandu showed that as many as 11 toddlers were malnourished, this was due to the low knowledge of mothers regarding the balanced nutrition of toddlers, poor attitudes in fulfilling balanced nutrition for toddlers, and poor culture in fulfilling toddler nutrition. The main target of this program is assistance for the formation and training of Breastfeeding Mothers' Groups in an effort to improve the health status of mothers, babies and toddlers in Penyengat Olak Village, Kec. Jambi Outside the City. The output of this program is there is an increase in community participation in improving the health of mothers and children by assisting the formation of groups of breastfeeding mothers. The implementation of the activity was started with an observation of the breastfeeding mothers research group in several Penyengat Olak village which consisted of 3 breastfeeding mothers' groups, namely in the RT. 18, RT 19, and RT 20. Each group consists of 10 people consisting of pregnant women and nursing mothers. It is hoped that the continuity of breastfeeding mother's breastfeeding program can be maintained, even though there are many factors raised by members, such as being busy taking care of the house and children, inappropriate meeting times, long distances, and so on.
\end{abstract}

Keywords: breastfeeding, breastfeeding support groups

\begin{abstract}
Abstrak
Kesehatan ibu dan anak merupakan salah satu aspek yang prioritas untuk diperhatikan. Berdasarkan hasil survey demografi dan Kesehatan Indonesia (SDKI) tahun 2012 menunjukkan bahwa angka kematian neonates pada tahun 2012 adalah 19 per 1000 kelahiran hidup. Masalah ini timbul diantaranya berkaitan dengan masalah pemberian ASI. Hasil skrining status gizi balita di posyandu menunjukkan bahwa sebanyak 11 balita mengalami gizi kurang, hal ini disebabkan karena pengetahuan ibu masih rendah terkait gizi seimbang balita, sikap yang kurang baik dalam pemenuhan gizi seimbang balita, serta budaya yang kurang baik dalam pemenuhan gizi balita. Target utama dari program ini adalah pendampingan pembentukan dan pelatihan Kelompok Ibu Menyusui dalam upaya meningkatkan derajat kesehatan ibu, bayi dan balita di Desa Penyengat Olak, Kec. Jambi Luar Kota. Luaran dari program ini adalah adanya peningkatan peran serta masyarakat dalam meningkatkan kesehatan ibu dan anak melalui pendampingan pembentukan kelompok ibu menyusui. Pelaksanaan kegiatan diawali dengan obsevasi kegiatan KP Ibu Menyusui di beberapa Kelurahan Penyengat Olak yang terdiri dari 3 KP Ibu Menyusui, yaitu di RT. 18, RT 19, dan RT 20. Masing-masing kelompok beranggotakan 10 orang yang terdiri dari ibu hamil dan ibu menyusui. Keberlangsungan dari KP Ibu Menyusui diharapkan dapat dipertahankan, meskipun banyak faktor yang dikemukakan anggota, misalnya kesibukan mengurus rumah dan anak, waktu pertemuan yang tidak sesuai, jarak yang jauh, dan lain sebagainya.
\end{abstract}

Kata Kunci: ASI, menyusui, kelompok pendukung ASI 


\section{PENDAHULUAN}

Kesehatan ibu dan anak merupakan salah satu aspek yang prioritas untuk diperhatikan. Masadepan anak sangat ditentukan oleh kesehatan sejak dalam kandungan dan pada masa balitanya.Kesehatan ibu hamil perlu diperhatikan mengingat masih banyaknya kejadian komplikasipada kehamilan dan persalinan yang akan berdampak pada kesehatan bayi yang dilahirkannya.Begitu pula kemampuan perawatan bayi baru lahir, pemenuhan ASI ekslusif dan giziseimbang pada balita sangat penting diperhatikan untuk menjamin kesehatan danperkembangannya.

Masalah kesehatan pada bayi dan balita juga membutuhkan perhatian mengingat angka kematian bayi dan balita juga masih tinggi di Indonesia. Berdasarkan hasil survey demografi dan Kesehatan Indonesia (SDKI) tahun 2012 menunjukkan bahwa angka kematian neonates pada tahun 2012 adalah 19 per 1000 kelahiran hidup. Masalah ini timbul diantaranya berkaitan dengan masalah pemberian ASI. Masalah dalam pemberian ASI ekslusif di Indonesia juga membutuhkan perhatian dari tenaga kesehatan khususnya perawat.

Secara nasional cakupan pemberian ASI eksklusif di Indonesia pada bayi 0 - 6 bulan sudah mengalami peningkatandari tahun ke tahun, namun belum dapat mencapai indikator pencapaian nasional. Cakupan pemberian ASI ekslusif di Indonesia pada tahun 2013 sebanyak 42\%, dan meningkat menjadi $65 \%$ di tahun 2016 , akan tetapi masih belum mencapai target Nasional pencapaian ASI eksklusif adalah 80\% (Kemenkes RI, 2016).

Kondisi ini salah satunya disebabkan olehminimnya kesadaran ibu terhadap pentingnya pemberian ASI ekslusif dan kurangnyadukungan ibu dalam pemberian ASI ekslusif terutama pada ibu yang bekerja.Masalah lain yang berkaitan dengan kesehatan ibu dan balita adalah dalam hal gizi balita.Masalah gizi pada populasi balita masih menjadi fokus perhatian masyarakat global. Angkakejadian gizi kurang dan gizi buruk masih selalu timbul meskipun berbagai usahapenatalaksanaan sudah dijalankan. Berdasarkan data WHO (2013), jumlah penderita kuranggizi di dunia mencapai 104 juta anak.

Keadaan kurang gizi ini menjadi penyebab sepertigadari seluruh penyebab kematian anak di seluruh dunia. WHO memperkirakan sebanyak 54\%kematian anak di dunia disebabkan oleh keadaan gizi yang buruk.Di Indonesia, gizi buruk menyebabkan lebih dari $80 \%$ kematian pada anak (WHO, 2011).

Permasalahan gizi kurang pada balita juga masih menjadi masalah aktual di berbagai provinsidi Indonesia. Wilayah provinsi yang belum terlepas dengan masalah gizi kurang sampaidengan buruk pada balita adalah Jambi. Angka statistik vitalmenunjukkan tingginya prevalensi balita gizi kurang yaitu sebesar 8,45 \% dan gizi buruksebesar 0,56\% pada tahun 2012 (Pusdatin Kemkes, 2017). Meskipun angka gizi kurang di Jambi telah jauh melampaui target nasional (persentase gizi kurang sebesar $15,5 \%$ di tahun 2016)namun penderita gizi buruk masih juga dijumpai di beberapa daerah di Jambi.

Berdasarkan fenomena tersebut dapat disimpulkan bahwa masalah kesehatan pada ibu dananak merupakan permasalahan utama dan bersama yang menjadi kepedulian negara, pemerintah provinsi Jambidan kabupaten Muaro Jambi. Untuk mengatasi haltersebut diperlukan pembentukan kelompok pendukung ibu yang menyusui untuk dapat menyusuibayinya. Seorang ibu yang memilikipengalaman menyusui akan memberikaninformasi, pengalaman dan menawarkanbantuan kepada ibu lainnya dalam kondisisaling percaya dan menghargai. PesertaKelompok Pendukung ASI adalahibu menyusui dan ibu-ibu lainnya yang mengeksplorasibeberapa 
pilihan untuk mendukungkeberhasilan menyusui.

Metode yang digunakan disebutdukungan sebaya (peer support) pada kelompok berbasis masyarakatyang terdiri dari ibu hamil atau ibu menyusuidengan anak 0-6 bulan berjumlah 8-10 orang dengan mengadakan pertemuan rutin setiap bulan untuk berbagi pengalaman, ide atauinformasi seputar kehamilan, melahirkan danmenyusui. Tujuan KP ibuadalah agar ibubisa melakukan IMD dan memberikan ASI secara lancar, serta menggalakkan ASI eksklusif. Bayi yang mendapat ASI Eksklusifselama 6 bulan secara signifikanmenurunkan resiko terjadinya diare, danmenurunkan resiko ISPA, dibandingkan bayiyang tidak mendapatkan ASI eksklusif (S. Mihrshahi, 2008).

Pertemuan ini diadakandalam suasana saling mendukung danpercaya dan fasilitasi oleh konselor temansebaya, dimana konselor tersebut memilikiminat untuk berbagi pengalaman, ide daninformasi seputar menyusui dan hal-hal yangmenjadi pendukung dan penghambat sertapermasalahan selama menyusui.Konseling yang dilakukanoleh teman sebaya lebih mudah diterimadimasyarakat. Ibu-ibu senang memilikiseseorang dimasyarakat yang dapatmembantu dalam problema menyusu.

Berdasarkan hasil survey yang sudah dilakukan melalui metode observasi dan wawancara kepada ibu dan balita di Desa Penyengat Olak pada tanggal 09 s.d 11 September 2019, diperoleh bahwa sebanyak 8 dari $10 \mathrm{ibu}$, mengatakan bahwa belum paham mengenai apa saja tanda komplikasi pada bayi baru lahir dan saat menyusui. Hasil wawancara terhadap 5 ibu balita mengatakan bahwa sudah memberikan makanan pendamping ASI sebelum anak berusia 6 bulan. Beberapa ibu mengeluhkan tidak memberikan ASI ekslusif karena bekerja. Hasil skrining status gizi balita di posyandu menunjukkan bahwa sebanyak 11 balita mengalami gizi kurang, hal ini disebabkan karena pengetahuan ibu masih rendah terkait gizi seimbang balita, sikap yang kurang baik dalam pemenuhan gizi seimbang balita, serta budaya yang kurang baik dalam pemenuhan gizi balita.

\section{TARGET DAN LUARAN}

Target utama dari kegiatan ini adalah pendampingan pembentukan dan pelatihan Kelompok Ibu Menyusui dalam upaya meningkatkan derajat kesehatan ibu, bayi dan balita di Desa Penyengat Olak, Kec. Jambi Luar Kota. Hal ini bertujuan untuk meningkatkan pengetahuan dan keterampilan ibu dalam menjaga kesehatan ibu dan bayinya selama mulai hamil sampai masa menyusui.

Adapun luaran dari kegiatan ini adalah adanya peningkatan peran serta masyarakat dalam meningkatkan kesehatan ibu dan anak melalui pendampingan pembentukan kelompok ibu menyusui, dengan indikator keberhasilan program:

1. Pendampingan terbentuknya kelompok ibu menyusui yang beranggotakan ibu hamil, ibu menyusui dan ibu dengan balita.

2. Adanya peningkatan pengetahuan tentang kesehatan tentang masalah kehamilan dan menyusui pada ibu.

3. Bagi ibu yang memiliki bayi usia 0-6 bulan dan sudah memberikan ASI secara eksklusif, tetap termotivasi untuk terus memberikan ASI.

4. Bagi ibu yang memiliki bayi usia 0-6 bulan dan sudah memberikan ASI dengan tambahan susu formula atau MP ASI, dapat termotivasi untuk meningkatkan pemberian ASI dan mengurangi pemberian susu formula atau MP ASI.

5. Bagi ibu yang memiliki bayi usia 0-6 bulan dan tidak memberikan ASI dapat termotivasi untuk mulai memberikan ASI kembali. 
6. Bagi ibu menyusui dapat mengetahui cara memerah ASI, menyimpan ASI, cara stimulasi pemberian ASI

7. Bagi ibu yang memiliki balita dapat mengetahui gizi seimbang balita, tanda gejala masalah gizi balita, dan stimulasi pertumbuhan \& perkembangan balita.

\section{METODE PELAKSANAAN}

Kegiatan ini dilaksanakan di rumah kader Posyandu yang berada di RT 19. Pelaksanaan kegiatan dilakukan di bulan September s.d November 2019, dengan metode sebagai berikut:

1. Observasi kegiatan ibu menyusui dan membagi dalam 3 kelompok.

2. Pendekatan inovatif berupa peer supportdalam pelakanaan kegiatan pelayanan kesehatan mulai pembentukan pengembangan KP Ibu Menyusui, melakukan MMD dan melakukan advokasi pada Kelurahan Penyengat Olak.

3. Persiapan dalam pembuatan buku saku, booklet dan modul/panduan konselor peer support.

4. Memberikan pelatihan peer support tentang metode pemecahan masalah menyusui.

5. Metode yang digunakan ceramah interakif, brainstorming dan aplikasi identifikasi masalah menyusui serta alternatif pemecahan.

6. Evaluasi sebelum dan sesudah pelatihan.

7. Melakukan pertemuan KP Ibu Menyusui dan melakukan implementasi konselor/ kunjungan rumah/home visit ibu menyusui ke rumah ibu menyusui.

8. Monitoring dan evaluasi pelaksanaan serta rencana tindak lanjut pemecahan masalah menyusui.

\section{HASIL DAN PEMBAHASAN}

Pelaksanaan kegiatan diawali denganobsevasi kegiatan KP Ibu Menyusui di beberapaKelurahan Penyengat Rendah yang tediri dari $3 \mathrm{KP}$ Ibu Menyusui, yaitu di RT. 18, RT 19, dan RT 20. Masingmasing kelompok beranggotakan 10 orang yang terdri dari ibu hamil dan ibu menyusui. Observasi dilaksanakan oleh ketua pelaksanadidampingi oleh bidan desa dan kader.

Hasil observasi dari 3 kelompok terdapat anggota kelompokyang hanya hadir 1 kali dari 3 kali kegiatan, namun hal ini tidak mengganggu motivasi anggota lainnya. Kehadiran anggota setiap kelompok pada setiap pertemuan $60-70 \%$. Bagi ibu yang selalu hadir, kelompok ini menyenangkan dan dapat memberikan solusi bagi ibu dan bayinya yang berhubungan dengan ASI.

Keberlangsungan dari KP Ibu Menyusui diharapkan dapat dipertahankan, meskipun banyak faktor yang dikemukakan anggota, misalnya kesibukan mengurus rumah dan anak, waktu pertemuan yang tidak sesuai, jarak yang jauh, dan lain sebagainya.

\section{Pendekatan}

inovatif

dalampelaksanaan kegiatan pelayanankesehatan dilakukan melalui edukasi dan implementasi. Upaya pendekatanedukatif dimulai dengan pencatatanjumlah kelompok sebaya yangdiperoleh dari seluruh masyarakat di Kelurahan Penyengat Olak yang mana dari merekamemenuhi kriteria untuk menjadi peserta KP Ibu Menyusui. Pendataan dibantuoleh bidan desa Penyengat Olak sehingga setelah memperolehdata, team pengabdian masyarakatmelakukan survei mawas diri yangbertujuan untuk memotivasikeikutsertaan mereka dalam kegiatanpengabdian. Hasilnya respon positifdari kelompok sebaya danmendukung untuk pelaksanaankegiatan tersebut yang didukungkesadaran mereka dalam upayakesehatan peningkatan pemberian ASI Eksklusif.

Luaran yang diharapkan dari kegiatan ini adalah terbentuknya KP Ibu Menyusui di Kelurahan Penyengat Rendah yang mampu berperan dalam pemberian ASI 
eksklusif sampai anak berumur 6 bulan dan pemberian ASI dengan pendampingan sampai anak umur 2 tahun. Kegiatan ini di danai oleh DIPA Poltekkes Kemenkes Jambi dan akan dipublikasi dalam bentuk proceeding atau pada Jurnal ISSN.

\section{KESIMPULAN DAN SARAN 1. Kesimpulan}

Salah satu upaya peningkatan cakupan jumlah bayi yang diberi ASI eksklusif dengan upaya pelatihan KP Ibu Menyusui sebagai salah satu upaya pemberdayaan masyarakat.Terbentuk Kelompok Pendukung Ibu Menyusui diharapankan bisa lebih aktif dalam pemberdayaan masyarakat dan meningkatkan kemampuan dan ketrampilannya dalam mengatasi masalah menyusui serta melakukan implementasi yang berkesinambungan pada kelompok KP Ibu Menyusui serta mampu menjadi konselor teman sebaya secaraberkelanjutan.

\section{Saran}

Diharapkan KP Ibu Menyusui dapat meningkatakan keaktifan kegiatan dan penambahan materi yang up date sehingga meningkatkan wawasan masyarakat. Dengan adanya peningkatan kreakifitas dan inovasi KP Ibu Menyusuiakan membantu keberhasilan Asi Eksklusif.

\section{UCAPAN TERIMA KASIH}

Pelaksanaan kegiatan ini berjalan lancar dengan adanya dukungan dari perangkat Desa Penyengat Olak, kader Posyandu, Bidan Koordinator KIA dan staf Puskesmas Penyengat Olak, serta mahasiswa dan dosen Jurusan Kebidanan Poltekkes Kemenkes Jambi.

\section{DAFTAR PUSTAKA}

Abate, H.G., Makau, K., \& Sorensen. P., (2005). Risk factor for child undernutrition with a human right edge in rural villages of north wollo, ethiophia. East African Medical
Journal. Vol 82, No 12, December 2005

Allender, J.A \& Spradley, B.W. (2014). Community health nursing: promoting and protecting the public health, 8th edition. Philadelphia: Lippincott

Helvie (1998). Advanced practice nursing in the community. Sage Publications, Inc: California

Kemenkes RI (2010). Rencana Strategis Kemenkes Tahun 2010-2014.

Kemenkes RI: Jakarta

Kemenkes RI (2013). Rencana Kerja Pembinaan Gizi Masyarakat Tahun 2013. Direktorat Bina Gizi dan KIA. Kementerian Kesehatan RI

Kemenkes RI (2014). Pedoman Gizi Seimbang. Direktorat Bina Gizi dan KIA. Kementerian Kesehatan RI

Laksmi, T, 2012. Hubungan kelompok Pendukung ibu dalam meningkatkan Perilaku ASI Ekslusif di kelurahan Banguntapan, Kecamatan Banguntapan, Kabupaten Bantul DI. Yogyakarta. FKM. UI 